\title{
Incongruence between the distribution of a common coral reef sponge and photosynthesis
}

\author{
R. J. Bannister ${ }^{1,2,6, *}$, M. O. Hoogenboom ${ }^{3}$, K. R. N. Anthony ${ }^{4}$, C. N. Battershill ${ }^{2,5}$, \\ S. Whalan ${ }^{1}$, N. S. Webster ${ }^{5}$, R. de Nys ${ }^{1,2}$ \\ ${ }^{1}$ School of Marine and Tropical Biology, and ${ }^{2}$ AIMS@JCU Tropical Aquaculture Program, James Cook University, \\ Townsville, Queensland 4811, Australia \\ ${ }^{3}$ Faculty of Biomedical and Life Sciences, University of Glasgow, Glasgow, UK \\ ${ }^{4}$ Center for Marine Studies, University of Queensland, St Lucia, Queensland 4072, Australia \\ ${ }^{5}$ Australian Institute of Marine Science, PMB 3, Townsville, Queensland 4810, Australia \\ ${ }^{6}$ Present address: Institute of Marine Research, PO Box 1870, 5817 Bergen, Norway
}

\begin{abstract}
Symbiosis between coral reef fauna and microorganisms drives the growth, maintenance and diversity of coral reef habitats. Sponges, a key faunal component of coral reefs, form complex symbiotic relationships with microorganisms which may supply over half of their nutritional requirements through photosynthesis. The habitat distribution of the coral reef sponge Rhopaloeides odorabile correlates with light availability, suggestive of photosynthesis. The present study directly investigated the hypothesis that habitat distribution of $R$. odorabile is correlated with photosynthesis. Results of photorespirometry trials of 30 ind. exposed to light intensities between 0 and $900 \mu \mathrm{mol}$ photons $\mathrm{m}^{-2} \mathrm{~s}^{-1}$ showed no evidence of photosynthesis. Furthermore, no photopigments were present in these sponges and no cyanobacteria could be detected within the tissue. These results did not vary between sponges collected from nutrient rich inner- and mid-shelf reefs, or from oligotrophic outershelf reefs. These findings demonstrate that $R$. odorabile is not a phototrophic sponge and that habitat distributions clearly correlated with light can be due to factors other than photosynthesis.
\end{abstract}

KEY WORDS: Symbiosis · Photosynthesis · Porifera · Rhopaloeides odorabile · Great Barrier Reef · Cyanobacteria

Resale or republication not permitted without written consent of the publisher

\section{INTRODUCTION}

Animal-plant and animal-microbial symbioses are common in tropical benthic communities and facilitate the growth, maintenance and diversity on coral reefs through photosynthetic productivity, mineral recycling and the production of carbonate skeletons (Smith \& Douglas 1987). Many sponge species form symbioses with microorganisms, including filamentous cyanobacteria, zooxanthellae, diatoms and unicellular algae (reviewed by Sarà et al. 1998). In addition, sponges have complex and highly specific interactions with a consortium of bacteria that contribute to their nutrition, including the assimilation of dissolved organic carbon and nitrogen (DOC and
DON) and photosynthetically derived carbon (reviewed in Taylor et al. 2007, Bell 2008). Cyanobacteria are the most common photosynthetic symbionts of sponges on the Great Barrier Reef (GBR) (Wilkinson 1978), in some cases providing phototrophic sponges with at least $50 \%$ of their nutrition as fixed carbon from photosynthesis (Wilkinson 1983, reviewed in Taylor et al. 2007, Erwin \& Thacker 2008). Other benefits of sponge-microbe associations include nitrification, methane oxidation, sulfate reduction, UV protection, enhanced boring and growth rates, secondary metabolite production and dehalogenation processes (reviewed in Taylor et al. 2007).

On coastal coral reefs of the GBR, the majority of sponges are heterotrophic, whilst those found on off- 
shore reefs are predominantly phototrophic or mixotrophic (Wilkinson \& Trott 1985, Wilkinson 1987, Wilkinson \& Cheshire 1989). It has been suggested that the prevalence of heterotrophic sponges on coastal reef habitats is due to increased suspended sediments, higher nutrient levels and reduced light availability associated with land-based runoff (Wilkinson \& Cheshire 1989, Cleary \& de Voogd 2007). In contrast, clear water leads to a dominance of phototrophic sponges on offshore reefs where the higher light intensities provide the carbon required for growth and survival (Wilkinson \& Trott 1985, Cleary \& de Voogd 2007).

Rhopaloeides odorabile is a common reef-associated sponge that colonises both inshore and offshore reefs (Wilkinson \& Cheshire 1989, Bannister et al. 2010) and displays distinct morphs between locations (Thompson et al. 1987). On coastal reefs, $R$. odorabile are slender and show partial surface depigmentation, whereas on offshore reefs $R$. odorabile are large and have dark reddish-brown surface pigmentation, characteristic of sponges harbouring symbiotic cyanobacteria (Giano et al. 1977, Wilkinson 1980). Furthermore, the culturable microbial community of $R$. odorabile has been isolated and includes a unique cyanobacterium within the order Oscillatoriales (Webster \& Hill 2001), as well as other microbial symbionts (Webster et al. 2001a,b). The cyanobacterium isolated from $R$. odorabile could not be enumerated, was never detected during extensive transmission electron microscopy (TEM) analysis and its role within $R$. odorabile remains unclear (Webster \& Hill 2001). The differential depth distribution of $R$. odorabile on exposed fore-reef slopes, offshore reefs (between 5 and $15 \mathrm{~m}$ ) and coastal reefs (<10 m) (Bannister et al. 2010) strongly suggests that a symbiotic relationship with cyanobacteria, or other potential photosymbionts, may restrict the distribution and abundance of $R$. odorabile through its reliance on a photosynthetic energy source. While this is a plausible hypothesis, there is no confirmation that light and photosynthesis play a critical role in determining the distribution of $R$. odorabile, or that photosynthesis even occurs.

Given that Rhopaloeides odorabile is one of the most studied sponge species, and in many cases is a model for sponge biology and ecology on the GBR, the present study aims to determine the role of light, by way of photosynthesis, as a factor affecting the distribution of $R$. odorabile across the continental shelf of the central GBR. It specifically addresses the issue of whether $R$. odorabile individuals across inner-, midand outer-shelf reef locations possess photosymbionts and whether their presence/absence can explain the apparent light-driven distribution of $R$. odorabile between shelf locations.

\section{MATERIALS AND METHODS}

Collection of specimens. In January 2005, sponge explants were cut from 10 Rhopaloeides odorabile individuals at each of 3 reefs along a GBR shelf gradient: Pith Reef (outer-shelf reef), Rib Reef (mid-shelf reef) and Pelorus Island (inner-shelf reef). Five sponge explants were also cut from 5 Carteriospongia foliascens individuals, a known phototrophic sponge (Bergquist et al. 1988), at Rib Reef to use as a positive control for oxygen evolution measurements. At each location these explants were placed into plastic moulded recovery cages (Aqua-Tech) anchored to the sea floor at $9 \mathrm{~m}$ (the same depth at which these sponges were collected). Explants were left in these cages for $7 \mathrm{wk}$ to allow their damaged surfaces to heal and recover (Louden et al. 2007).

In March 2007, 7 wk after excising sponge explants, individual explants were collected and transported back to the aquarium facilities at James Cook University in aerated seawater. Sponges were placed into separate 301 aquaria ( 5 sponges aquarium ${ }^{-1}$ ) and acclimated at the same conditions for $3 \mathrm{~d}$ prior to conducting oxygen evolution measurements. Each aquarium had a mesh rack mounted on the bottom to maintain adequate water flow around the sponge explants and circulation was provided by a power-head pump (Aqua-clear 402). Seawater in the aquarium system was collected from the Australian Institute of Marine Science, Cape Cleveland, $50 \mathrm{~km}$ south of Townsville, and was filtered to $10 \mu \mathrm{m}$. Bio-filtration, foam fractionators and sand filters were used to maintain water quality. Each aquarium was illuminated on a $10 \mathrm{~h}$ light:14 h dark regime using $400 \mathrm{~W}$ metal halide lamps (Eye) at approximately $500 \mu \mathrm{mol}$ photons $\mathrm{m}^{-2} \mathrm{~s}^{-1}$, representative of near-natural light regimes (Fabricius \& Klumpp 1995, Cheshire et al. 1997).

Photophysiology. To quantify photosynthesis within the tissues of Rhopaloeides odorabile, oxygen evolution was measured using a set of 6 closed, recirculating perspex respirometry (flow) chambers (2.7 l) fitted with calibrated Clark-type oxygen electrodes (Cheshire Systems). For a detailed description of the respirometry system see Hoogenboom et al. (2006). Two suspended $400 \mathrm{~W}$ metal halide lamps (Eye) were used to adjust the light intensity over the respirometry chambers, exposing the sponges to 12 discrete light levels for 25 min periods $(0,15,40,60,100,120,200,290$, 420, 530, 710 and $900 \mu \mathrm{mol}$ photons $\mathrm{m}^{-2} \mathrm{~s}^{-1}$ ). Measuring across this range of light levels allows a good characterisation of the shape of the photosynthesisirradiance response (Hoogenboom et al. 2006), and is representative of light levels experienced on the GBR at the depths where $R$. odorabile are commonly found (Fabricius \& Klumpp 1995, Cheshire et al. 1997). Dis- 
crete light levels were measured using a LI-192S LICOR probe connected to a LI-1000 data logger. During each 25 min period, oxygen concentrations were recorded every 30 s onto a central data logger (CR10X Campbell Scientific), and chambers were flushed with new seawater for 5 min after each 25 min recording interval to maintain oxygen saturation above $85 \%$ and prevent oxygen supersaturation.

Oxygen evolution measurements were conducted over a period of 7 consecutive days, with 5 sponges measured each day. Temperature was maintained constant at 27 to $28^{\circ} \mathrm{C}$ by suspending the respirometry chambers in a 200 l water jacket connected to a thermostat regulated water chiller (Carrier Systems). On each day, 1 control explant (Carteriospongia foliascens) and 4 Rhopaloeides odorabile explants were used as collected from either of the inner-, mid- or outer-shelf treatments and randomly selected using a random-number table. One respirometry chamber was left empty during each experiment to control for photosynthesis and respiration of microorganisms within the water. Chambers were regularly cleaned to prevent biofilm formation (Hoogenboom et al. 2006). Whole explants were weighed immediately following each daily experiment to obtain wet weights (fresh weight, FW), and oxygen flux values were subsequently normalised by sponge weight $\left(\mu \mathrm{mol} \mathrm{O}_{2} \mathrm{~g} \mathrm{FW}^{-1} \mathrm{~h}^{-1}\right)$. Surface tissue samples $\left(1 \mathrm{~cm}^{3}\right)$ were collected from each sponge explant and frozen at $-40^{\circ} \mathrm{C}$ for later quantification of photopigments.

Photopigment extraction. To extract photopigments (chlorophyll $a_{1} c_{1}$ and $c_{2}$ and phycoerythrin), whole tissue samples were prepared following methods modified from Larkum et al. (1987). To extract water-soluble pigments (phycobiliproteins), tissue samples were frozen and thawed several times in ice-cold buffer (0.2 M phosphate, $\mathrm{pH}$ 7.4). Subsequently, to extract chlorophyll, tissue samples used for phycobiliprotein extractions were freeze-dried to remove excess water, crushed using liquid nitrogen and a mortar and pestle and then placed into cold $90 \%$ acetone for $24 \mathrm{~h}$. Both acetone and water-soluble extracts were centrifuged at $1000 \times g$ to obtain a clear supernatant. The supernatant from each extract was decanted and then scanned separately at wavelengths between 350 and $750 \mathrm{~nm}$ using an Agilent 8453 UV-visible spectrophotometer.

Cyanobacteria determination in Rhopaloeides odorabile. To enumerate quantitatively the presence of cyanobacteria within $R$. odorabile, sponge sections for TEM were excised from the pinacoderm to a depth of $0.5 \mathrm{~cm}$ into the mesohyl for all sponges sampled from Davies Reef ( $\mathrm{n}=6$; mid-shelf reef) and Pelorus Island ( $\mathrm{n}=4$; inner-shelf reef). Samples were cut into small pieces (ca. $1 \mathrm{~mm}$ diameter) and fixed in $0.1 \mathrm{M}$ sodium cacodylate buffer ( $\mathrm{pH}$ 7.4) prepared in artificial seawa- ter (ASW) and containing 2.5\% (v/v) glutaraldehyde for $20 \mathrm{~h}$. Fixed tissue samples were removed, placed in fresh $0.1 \mathrm{M}$ sodium cacodylate buffer and stored at $4^{\circ} \mathrm{C}$ until further processing. Fixed tissue samples were placed in a $1 \%$ (w/v) osmium tetroxide solution (prepared in 0.2 M potassium phosphate buffer, $\mathrm{pH}$ 7.4) for $3.5 \mathrm{~h}$ and subsequently dehydrated in a graded ethanol series $(15,35,55,75,85$ and $95 \%$ (v/v) ethanol). Tissue was embedded in Spurr's resin, sectioned with an ultramicrotome and stained with $2 \%(\mathrm{w} / \mathrm{v})$ uranyl acetate followed by $0.2 \%(\mathrm{w} / \mathrm{v})$ lead citrate. Sections were mounted on 200-mesh copper grids coated with carbon and Formvar. Samples were visualised by TEM (Jeol 2000 FX). Between 18 and 25 fields of view from each sponge sampled were assessed for the presence of cyanobacteria.

Statistical analysis. To quantify the dependence of net photosynthesis rate on irradiance, the hyperbolic tangent model was fitted to photosynthesis data. The model fits were conducted using a non-linear estimation routine in the software package Statistica (StatSoft 1999). The hyperbolic tangent model (our Eq. 1, Jassby \& Platt 1976) was chosen, because it generally provides the best fit (highest $\mathrm{r}^{2}$ values) to photosynthesis versus irradiance $(P-I)$ data (Chalker 1981) in the absence of photoinhibition beyond the irradiance at which saturation $\left(I_{k}\right)$ occurs.

$$
P_{\mathrm{n}}=P_{\max } \tanh \left(I / I_{k}\right)-R_{\text {dark }}
$$

where $P_{\mathrm{n}}$ is the hourly rate of photosynthesis $\left(\mu \mathrm{mol} \mathrm{O}_{2}\right.$ $\left.\mathrm{g} \mathrm{FW}^{-1} \mathrm{~h}^{-1}\right), R_{\text {dark }}$ is the rate of respiration in darkness $\left(\mu \mathrm{mol} \mathrm{O} \mathrm{g} \mathrm{FW}^{-1} \mathrm{~h}^{-1}\right), P_{\max }$ is the maximum rate of photosynthesis ( $\mu \mathrm{mol} \mathrm{O} \mathrm{g} \mathrm{FW}^{-1} \mathrm{~h}^{-1}$ ), $I$ is irradiance $(\mu \mathrm{mol}$ photons $\mathrm{m}^{-2} \mathrm{~s}^{-1}$ ) and $I_{k}$ is the sub-saturation irradiance ( $\mu$ mol photons $\mathrm{m}^{-2} \mathrm{~s}^{-1}$ ). Where the hyperbolic tangent model did not adequately capture the variation in the photosynthesis data (i.e. if photosynthesis did not increase asymptotically with increasing irradiance), simple linear regressions were also fitted to the oxygen evolution data to detect if there was any light-dependent change in respiration activity of inner-, mid- and outer-shelf reef sponge explants.

\section{RESULTS AND DISCUSSION}

Rhopaloeides odorabile does not display typical photosynthetic-irradiance responses of sponges containing photosymbionts (Fig. 1) and the shelf location of the reef from which individual sponges originated did not influence this result. Even for sponges collected from oligotrophic, outer-shelf locations, we did not observe any positive net photosynthesis (Fig. 1). Although a cyanobacterium has previously been isolated from $R$. odorabile tissue and identified by $16 \mathrm{~S}$ rRNA 
sequence analysis (Webster \& Hill 2001), the abundance of cyanobacteria within tissue sections was not empirically determined. In the present study, extensive analysis of TEM micrographs from replicate sponges at 2 shelf locations did not identify cyanobacteria in either the pincoderm or mesohyl matrix (Fig. 2). Furthermore, molecular analysis of $>85000$ sequences of $R$. odorabile symbionts showed that cyanobacteria comprise $<0.71 \%$ of the sequenced microbial community (Webster et al. 2010).

Several studies have linked the photosynthetic activity of marine sponges to the presence of cyanobacteria within the tissues (Wilkinson 1983, Cheshire et al. 1997, Erwin \& Thacker 2008). Nevertheless, even if present in Rhopaloeides odorabile, photosymbionts do not provide this species with carbon generated through photosynthesis. This is unequivocally demonstrated by the absence of a relationship between net oxygen exchange rate and light intensity ranging between 0 and $900 \mu \mathrm{mol}$ photons $\mathrm{m}^{-2} \mathrm{~s}^{-1}$ (Fig. 1) for $R$. odorabile individuals from inner- $\left(\mathrm{r}^{2}=0.11, \mathrm{n}=10\right.$, $\mathrm{p}=0.274)$, mid- $\left(\mathrm{r}^{2}=0.28, \mathrm{n}=10, \mathrm{p}=0.060\right)$ and outershelf reef locations $\left(\mathrm{r}^{2}=0.18, \mathrm{n}=10, \mathrm{p}=0.154\right)$. In contrast, Carteriospongia foliascens, a sponge with multiple species of cyanobacterial symbionts (Steindler et al. 2005), displayed the typical $P$ - $I$ response curve that was well characterised by the photosynthesis model $\left(\mathrm{r}^{2}>0.98\right.$; Fig. 1). In fact, this species showed strong photosynthetic activity with a maximum rate of net photosynthesis that was more than 4 times greater than the rate of respiration in darkness (Table 1), corresponding well to other studies investigating $P-I$ responses for other phototrophic coral reef sponges

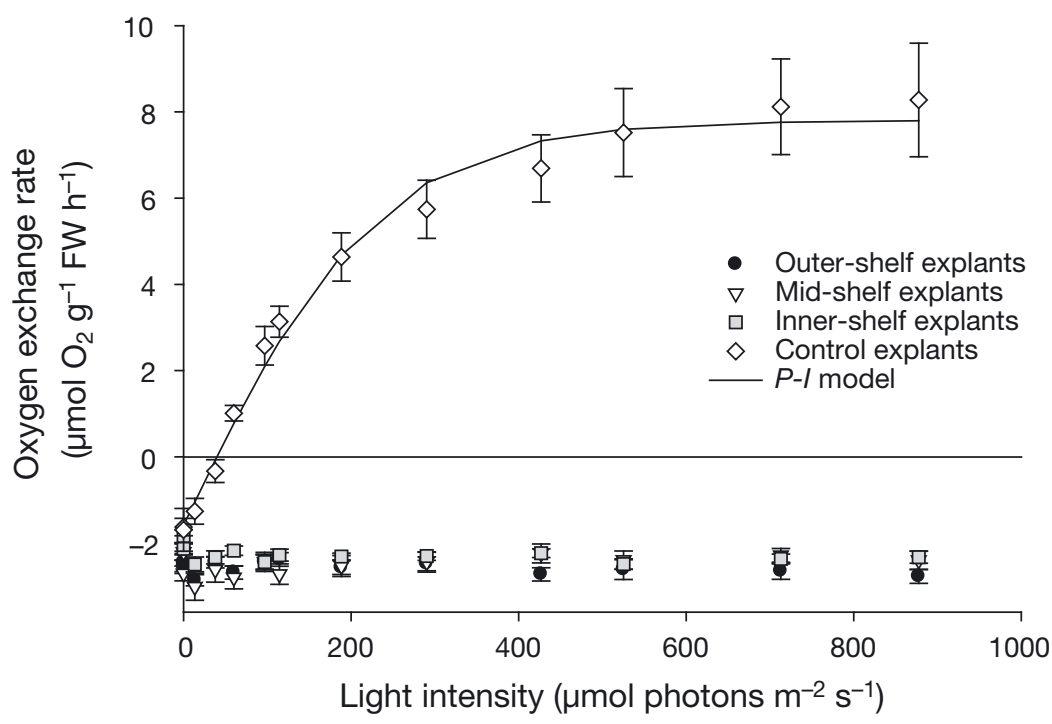

Fig. 1. Rhopaloeides odorabile and Carteriospongia foliascens. Photosynthesis versus irradiance $(P-I)$ curves for $R$. odorabile from inner-, mid- and outer-shelf locations (each, $\mathrm{n}=10$ ) and the control sponge $C$. foliascens $(\mathrm{n}=5)$. Error bars represent SE of the mean. FW: fresh weight

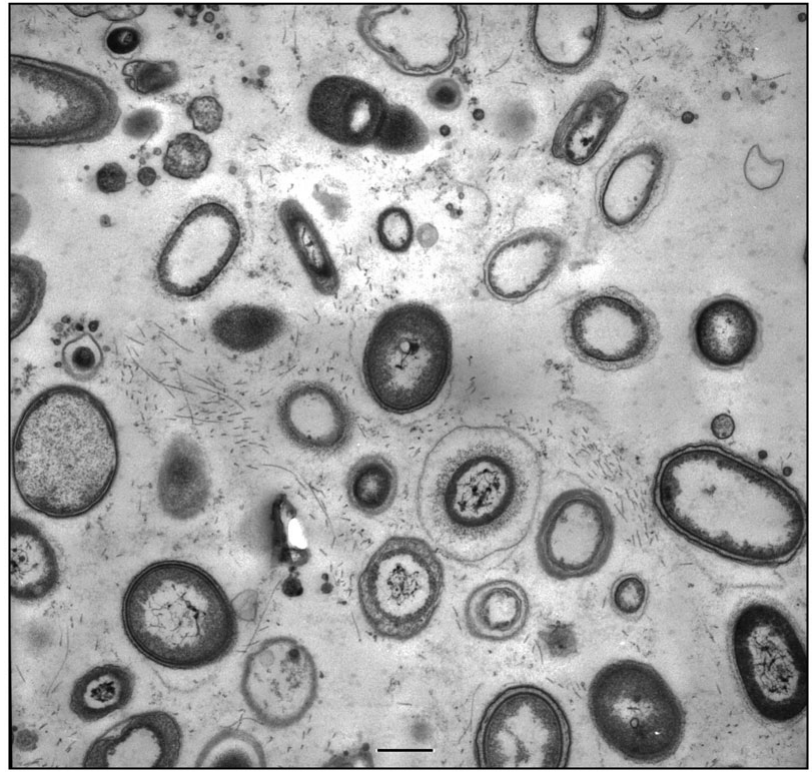

Fig. 2. Rhopaloeides odorabile. Transmission electron micrograph of $R$. odorabile depicting the bacterial community within the mesohyl from the upper $0.5 \mathrm{~cm}$ of sponge tissue. Scale bar $=0.4 \mu \mathrm{m}$

(Wilkinson 1983, Cheshire \& Wilkinson 1991, Erwin \& Thacker 2008).

The results of the present study also demonstrate that photosynthetic pigments, including chlorophylls and red and blue phycobiliproteins, are not present within the surface tissues of Rhopaloeides odorabile (Fig. 3). Surprisingly, in light of the differences in surface coloration for sponges collected from different locations, absorbance profiles of sponges from inner-, mid- and outer-shelf reefs were not strongly different. These results highlight the fact that sponge-microbe symbioses are highly complex. Indeed, only a handful of studies have elucidated the key roles of microbial consortia to sponge physiology, which include UV protection, enhanced boring and growth rates, metabolite production, and most importantly, nutrient and carbon acquisition (reviewed in Taylor et al. 2007, Erwin \& Thacker 2008). Nevertheless, the latter does not appear to be the case for the common and abundant reef-associated sponge $R$. odorabile, which suggests that (1) the cyanobacterium is an inhabitant of the surrounding seawater inadvertently filtered by the sponge; (2) the sponge-cyanobacterial association is commensal as is the case for some other coral reef sponge-cyanobacterial asso- 
Table 1. Carteriospongia foliascens. Non-linear estimations of steady-state sub-saturation irradiance $\left(I_{k}\right)$ and steady-state maximum rate of gross photosynthesis $\left(P_{\max }\right)$ for the control sponge. $R_{\text {dark }}$ : rate of respiration in darkness; FW: fresh weight

\begin{tabular}{|c|c|c|c|}
\hline & Estimate & $\mathrm{SE}$ & $\mathrm{p}$ \\
\hline$P_{\max }\left(\mu \mathrm{mol} \mathrm{O} \mathrm{O}^{-1} \mathrm{FW} \mathrm{h}^{-1}\right)$ & 9.386 & 0.304 & $<0.001$ \\
\hline$I_{k}\left(\mu \mathrm{mol}\right.$ photons $\left.\mathrm{m}^{-2} \mathrm{~s}^{-1}\right)$ & 233.691 & 12.447 & $<0.001$ \\
\hline$R_{\text {dark }}\left(\mu \mathrm{mol} \mathrm{O} \mathrm{g}^{-1} \mathrm{FW} \mathrm{h}^{-1}\right)$ & 1.582 & 7.012 & $<0.001$ \\
\hline
\end{tabular}

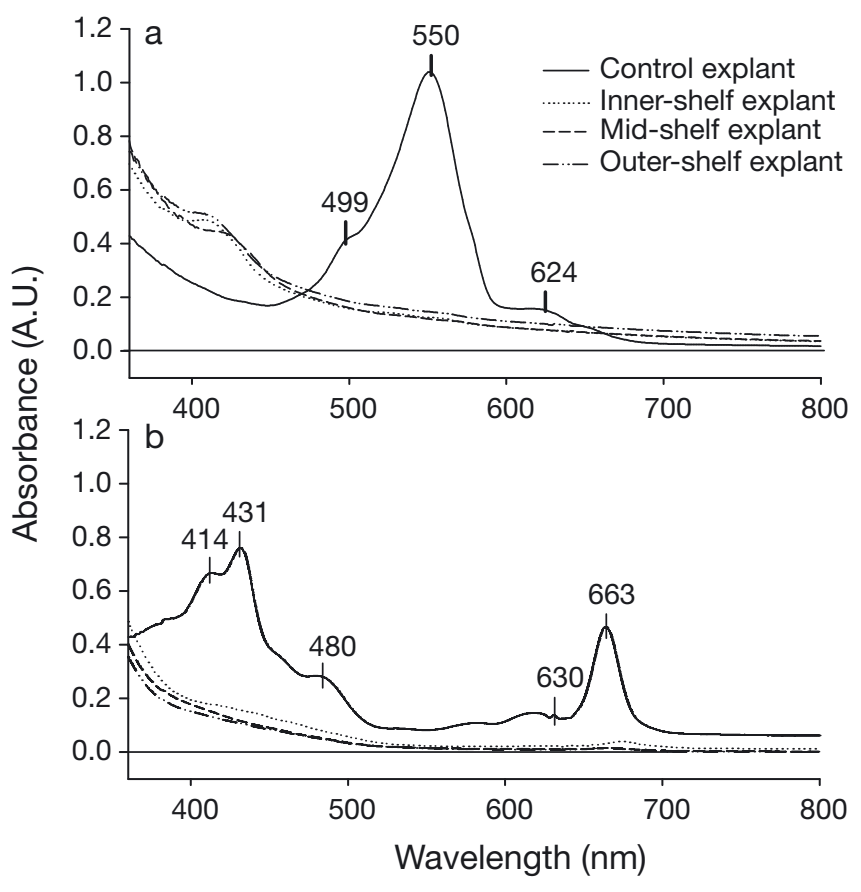

Fig. 3. Rhopaloeides odorabile and Carteriospongia foliascens. (a) Mean absorbance spectra of water-soluble pigments for inner-, mid- and outer-shelf reef explants (each, $n=10$ ) of $R$. odorabile and for explants of the control sponge C. foliascens $(\mathrm{n}=5)$. Pigments expressed between 500 and $600 \mathrm{~nm}$ wavelength are characteristically red phycobiliproteins (phycoerythrin; Jeffery \& Hallegraff 1990). (b) Mean absorbance spectra of acetone-extracted pigments for inner-, mid- and outer-shelf reef explants (each, $\mathrm{n}=10$ ) of $R$. odorabile and for explants of $C$. foliascens $(\mathrm{n}=5)$. Chlorophyll $a$ is at $664 \mathrm{~nm}$ and $c_{1}$ and $c_{2}$ at $630 \mathrm{~nm}$ (Jeffery \& Humphrey 1975)

ciations (e.g. Thacker 2005, López-Legentil et al. 2008); or (3) cyanobacteria may exhibit temporally variable relationships with $R$. odorabile.

As Rhopaloeides odorabile does not acquire additional energy through photosynthesis, energy and nutritional requirements are obtained through filter feeding. Therefore, it remains unclear what role, if any, light plays in determining the depth distribution of $R$. odorabile, which has highest abundance within the phototrophic zone (8 to $12 \mathrm{~m}$ depth; Bannister et al.
2010). One explanation for this pattern may be that the depth distributions across shelf locations are regulated by light availability and larval settlement behaviours. Larvae of $R$. odorabile display positive phototactic behaviours prior to settlement, coinciding with a preference to settle on light-exposed surfaces (Whalan et al. 2008). Alternatively, changes in food availability associated with light may be driving the observed differential depth distributions of $R$. odorabile, since food availability can be linked to the distribution patterns of coral reef sponges (e.g. Lesser 2006). Furthermore, suspended sediments (turbidity) correlated with light availability (Anthony et al. 2004) may affect depth distributions on inner-shelf reefs.

In conclusion, Rhopaloeides odorabile does not possess active or beneficial photosymbionts, or they are not present in sufficient numbers for light-driven photosynthesis to be detected. Since several environmental factors can be correlated with light availability, distribution patterns strongly associated with light cannot automatically be assumed to invoke a phototrophic mode of nutrition.

Acknowledgements. We thank A. Mills and R. Hidlebaugh for assistance in the field with sample collection.

\section{LITERATURE CITED}

Anthony KRN, Ridd PV, Orpin AR, Larcombe P, Lough J (2004) Temporal variation of light availability in coastal benthic habitats: effects of clouds, turbidity, and tides. Limnol Oceanogr 49:2201-2211

Bannister RJ, Battershill C, de Nys R (2010) Demographic variability and long-term change in a coral reef sponge along a cross-shelf gradient of the Great Barrier Reef. Mar Freshw Res 61:389-396

Bell JJ (2008) The functional roles of marine sponges. Estuar Coast Shelf Sci 79:341-353

Bergquist PR, Ayling AM, Wilkinson CR (1988) Foliose Dictyoceratida of the Australian Great Barrier Reef. I. Taxonomy and phylogenetic relationships. PSZNI: Mar Ecol 9: 291-319

Chalker BE (1981) Simulating light-saturation curves for photosynthesis and calcification by reef-building corals. Mar Biol 63:135-141

Cheshire AC, Wilkinson CR (1991) Modelling the photosynthetic production by sponges on Davies Reef, Great Barrier Reef. Mar Biol 109:13-18

Cheshire AC, Wilkinson CR, Seddon S, Westphalen G (1997) Bathymetric and seasonal changes in photosynthesis and respiration of the phototrophic sponge Phyllospongia lamellosa in comparison with respiration by the heterotrophic sponge Ianthella basta on Davies Reef, Great Barrier Reef. Mar Freshw Res 48:589-599

Cleary DFR, de Voogd NJ (2007) Environmental associations of sponges in the Spermonde Archipelago, Indonesia. J Mar Biol Assoc UK 87:1669-1676

Erwin PM, Thacker RW (2008) Phototrophic nutrition and symbiont diversity of two Caribbean sponge-cyanobacteria symbioses. Mar Ecol Prog Ser 362:139-147 
Fabricius KE, Klumpp DW (1995) Widespread mixotrophy in reef-inhabiting soft corals: the influence of depth, and colony expansion and contraction on photosynthesis. Mar Ecol Prog Ser 125:195-204

Giano E, Pansini M, Pronzato R (1977) Aspetti dell'associazione fra Chondrilla nucula Schmidt (Demospongiae) e microorganismi simbionti (batteri e Cianoficee) in condizioni naturali e sperimentali. Cah Biol Mar 18:303-310

Hoogenboom MO, Anthony KRN, Connolly SR (2006) Energetic cost of photoinhibition in corals. Mar Ecol Prog Ser 313:1-12

Jassby AD, Platt R (1976) Mathematical formulation of the relationship between photosynthesis and light for phytoplankton. Limnol Oceanogr 21:540-541

Jeffery SW, Hallegraff GM (1990) Phytoplankton ecology of Australasian waters. In: Clayton MN, King RJ (eds) Biology of marine plants. Longman Cheshire, Melbourne, p 310-348

Jeffery SW, Humphrey GF (1975) New spectrophotometric equations for determining chlorophylls $\mathrm{a}, \mathrm{b}, \mathrm{c}_{1}$ and $\mathrm{c}_{2}$ in higher plants, algae and natural phytoplankton. Biochem Physiol Pflanz 167:191-194

Larkum AWD, Cox GC, Hiller RG, Parry DL, Dibbayawa TP (1987) Filamentous cyanophytes containing phycourobilin and in symbiosis with sponges and an ascidian of coral reefs. Mar Biol 95:1-13

Lesser MP (2006) Benthic-pelagic coupling on coral reefs: feeding and growth of Caribbean sponges. J Exp Mar Biol Ecol 328:277-288

López-Legentil S, Song B, McMurray SE, Pawlik JR (2008) Bleaching and stress in coral reef ecosystems: $h s p 70$ expression by the giant barrel sponge Xestospongia muta. Mol Ecol 17:1840-1849

Louden D, Whalan S, Evans-Illidge E, Wolff C, de Nys R (2007) An assessment of the aquaculture potential of the tropical sponges Rhopaloeides odorabile and Coscinoderma sp. Aquaculture 270:57-67

Sarà M, Bavestrello G, Cattaneovietti R, Cerrano C (1998) Endosymbiosis in sponges: relevance for epigenesis and evolution. Symbiosis 25:57-70

Smith DC, Douglas AE (1987) The biology of symbiosis. Edward Arnold, London

Steindler L, Huchon D, Avni A, Ilan M (2005) 16S rRNA phylogeny of sponge-associated cyanobacteria. Appl Environ Microbiol 71:4127-4131

Taylor MW, Radax R, Steger D, Wagner M (2007) Spongeassociated microorganisms: evolution, ecology, and bio-

Editorial responsibility: Joseph Pawlik, Wilmington, North Carolina, USA technological potential. Microbiol Mol Biol Rev 71: 295-347

Thacker RW (2005) Impacts of shading on sponge-cyanobacteria symbioses: a comparison between host-specific and generalist associations. Integr Comp Biol 45:369-376

Thompson JE, Murphy PT, Bergquist PR, Evans EA (1987) Environmentally induced variation in diterpene composition of the marine sponge Rhopaloeides odorabile. Biochem Syst Ecol 15:595-606

Webster NS, Hill RT (2001) The culturable microbial community of the Great Barrier Reef sponge Rhopaloeides odorabile is dominated by an $\alpha$-Proteobacterium. Mar Biol 138:843-851

- Webster NS, Watts JEM, Hill RT (2001a) Detection and phylogenetic analysis of novel crenarchaeote and euryarchaeote 16S ribosomal RNA gene sequences from a Great Barrier Reef sponge. Mar Biotechnol 3:600-608

> Webster NS, Wilson KJ, Blackall LL, Hill RT (2001b) Phylogenetic diversity of bacteria associated with the marine sponge Rhopaloeides odorabile. Appl Environ Microbiol 67:434-444

Webster NS, Taylor MW, Behnam F, Lücker S and others (2010) Deep sequencing reveals exceptional diversity and modes of transmission for bacterial sponge symbionts. Environ Microbiol 12:2070-2082

Whalan S, Ettinger-Epstein P, Battershill C, de Nys R (2008) Larval vertical migration and hierarchical selectivity of settlement in a brooding marine sponge. Mar Ecol Prog Ser 368:145-154

Wilkinson CR (1978) Microbial associations in sponges. Ecology, physiology and microbial populations of coral reef sponges. Mar Biol 49:161-167

Wilkinson CR (1980) Cyanobacteria symbiotic in marine sponges. In: Schwemmler W, Schenk HEA (eds) Endocytobiology, endosymbiosis and cell biology. Walter de Gruyter, Berlin, p 553-563

Wilkinson CR (1983) Net primary productivity in coral reef sponges. Science 219:410-412

> Wilkinson CR (1987) Productivity and abundance of large sponge populations on Flinders Reef flats, Coral Sea. Coral Reefs 5:183-188

Wilkinson CR, Cheshire AC (1989) Patterns in the distribution of sponge populations across the central Great Barrier Reef. Coral Reefs 8:127-134

Wilkinson CR, Trott LA (1985) Light as a factor determining the distribution of sponges across the central Great Barrier Reef. Proc 5th Int Coral Reef Symp, Tahiti 5:125-130

Submitted: August 7, 2010; Accepted: October 18, 2010

Proofs received from author(s): January 24, 2011 